\title{
Double-paddled pectoralis major myocutaneous flap as an alternative to microvascularized free flaps in complex orocervical defects
}

\author{
Manuel Moreno-Sánchez, Raúl González-García, Carlos Moreno-García \\ Department of Oral and Maxillofacial-Head and Neck Surgery, University Hospital Infanta Cristina, 06080 Badajoz, Spain.
}

Correspondence to: Prof. Raúl González-García, Department of Oral and Maxillofacial-Head and Neck Surgery, University Hospital Infanta Cristina, Avenida de Elvas s/n, 06080, Badajoz, Spain. E-mail: raulmaxilo@gmail.com

How to cite this article: Moreno-Sánchez M, González-García R, Moreno-García C. Double-paddled pectoralis major myocutaneous flap as an alternative to microvascularized free flaps in complex orocervical defects. Plast Aesthet Res 2017;4:82-5.

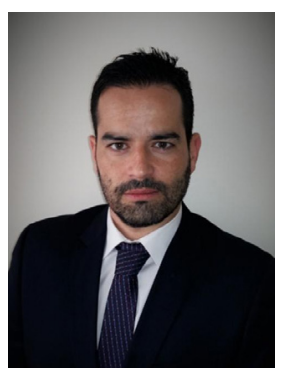

Prof. Raúl González-García, M.D., Ph.D, FEBOMFS, was graduated in Medicine (Medical Degree, M.D.) from the Universidad Autónoma de Madrid School of Medicine, Madrid, Spain, in 2001, and obtained his trainee in Oral and Maxillofacial Surgery in the University Hospital La Princesa, Madrid, Spain, in 2007. He obtained his Ph.D. Degree in Medicine and Surgery at the Universidad Autónoma de Madrid School of Medicine, in 2011. Since 2007 he is Consultant Surgeon at the Department of Oral and Maxillofacial Surgery, University Hospital Infanta Cristina, Badajoz, Spain, and he is also a University Honorary Collaborator at the Universidad de Extremadura School of Medicine. He is actually Editor-in-Chief of Plastic and Aesthetic Research, Assistant Director of Revista Española de Cirugía Oral y Maxilofacial, Permanent Member of the Reviewer Commitee of International Journal of Oral and Maxillofacial Surgery, Contributing Editor of Current Research in Dentistry, and Member of the Editorial Board/reviewer of more than 35 international journals of the speciality. He is author of more than 130 publications, 96 of them in international Medline/PubMed-indexed journals, 15 chapters in books of the speciality, and he is author of the text book "Reconstrucción Maxilomandibular Compleja: Microcirugía, Distracción Ósea e Implantes dentales".

Article history:

Received: 11-11-2016

Accepted: 25-04-2017

Published: 26-05-2017

Key words:

Double-paddled pectoralis flap, orocervical complex defect, microvascularized free flap failure

\begin{abstract}
The authors present the double-paddled pectoralis major myocutaneous flap as a successful alternative for the reconstruction of complex orocervical defects following failure of prior microvascularized free flaps or free flap harvest is not feasible. This method was used for the reconstruction of post-ablative defect in a 36-year-old male with a T4 squamous cell carcinoma of the base of tongue with laryngeal involvement. The distal paddle was adapted to reconstruct a defect of the floor of the mouth and further sutured in two layers (musclebasal mandible and skin paddle-oral mucosa) while the proximal skin paddle was used to close the cervical skin and the peri-tracheostomy defect.
\end{abstract}

cc) (1) 5 This is an open access article distributed under the terms of the Creative Commons AttributionCC NC SA NonCommercial-ShareAlike 3.0 License, which allows others to remix, tweak, and build upon the work non-commercially, as long as the author is credited and the new creations are licensed under the identical terms.

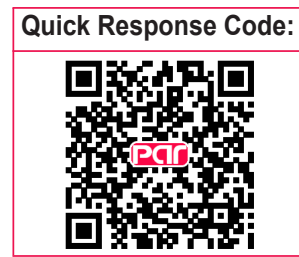

For reprints contact: service@oaepublish.com 


\section{INTRODUCTION}

Reconstruction of large oral cavity defects following resection for advanced cancer is a challenge for reconstructive surgeons. In the microsurgical era, microvascular free flaps constitute the main reconstructive option for achieving excellent aesthetic and functional results. However, in cases of flap failure or inability to harvest a free flap, pedicled flaps provide a reliable alternative with predictable results. The pectoralis major myocutaneous flap (PMMF), considered the workhorse in head and neck surgery, represents one such pedicled flap. In the event of major defects requiring a large area volume for cutaneous coverage and mucosal lining, a modification of the standard technique is required. ${ }^{[1-3]}$

\section{CASE REPORT}

The authors describe a surgical technique for repair of a complex orocervical defect following failure of microsurgical reconstruction with use of a doublepaddle PMMF. A 36-year-old man was diagnosed with T4 squamous cell carcinoma of the base of tongue with laryngeal involvement. Under general anaesthesia,

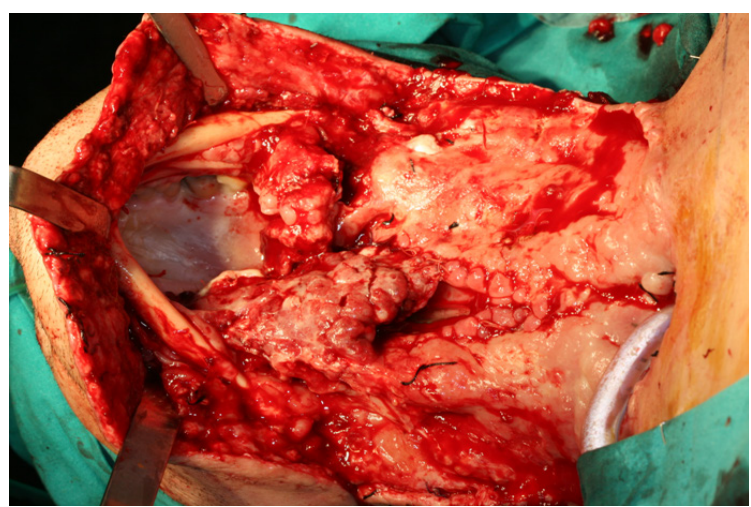

Figure 1: Distal flap dehiscence, cervical fistulae and large defect in the floor of the mouth following failure of a microsurgical anterolateral thigh flap

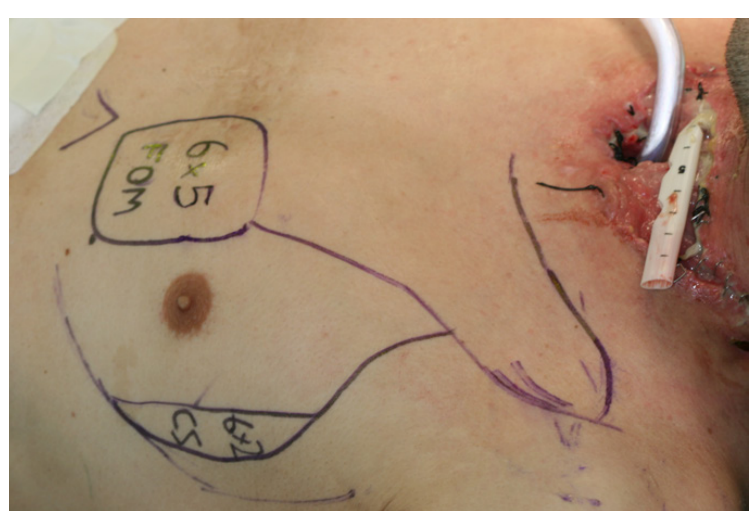

Figure 2: A pectoralis major myocutaneous flap design with two skin islands: one skin island was designed for the floor of the mouth defect with the other skin island for the cervical skin defect a tracheostomy was performed. A total laryngectomy and partial glossectomy extending to the right base of the tongue were performed by a "pull-through" approach exposing the entire tongue, oropharynx and suprahyoid space. A bilateral modified type III radical neck dissection was performed. The intraoral and primary cervical defects were reconstructed with a microsurgical anterolateral thigh flap. In the postoperative period, the remainder of the tongue underwent total necrosis with subsequent distal flap dehiscence, cervical fistulae and a large defect in the floor of the mouth [Figure 1]. In an attempt to solve these complications by providing sufficient tissue for reconstruction of the floor of the mouth while closing the orocervical fistulae, a PMMF with two skin islands was designed. This flap consisted of two vertically separated skin islands over the area of the pectoralis major myocutaneous vascular territory: one skin island was medial to the nipple-areolar complex and the other was lateral. The skin paddles were designed horizontally. The skin and the subcutaneous fat were closed using vicryl sutures to avoid shearing of perforator vessels vascularizing the skin. The flap was raised using standard surgical technique leaving its proximal paddle pedicled to the arterial plane [Figure 2]. The proximal skin paddle was used to close the cervical skin and the peri-tracheostomy defect [Figure 3A]. The distal paddle was adapted to floor of the mouth and sutured
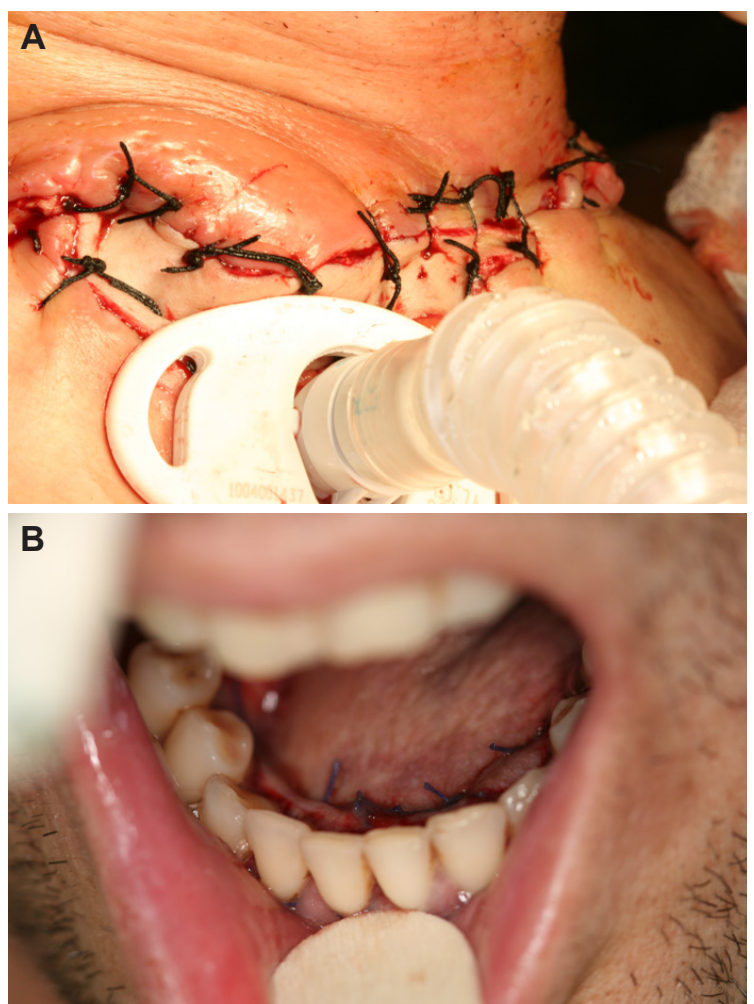

Figure 3: (A) The first skin paddle was used to close the cervical skin and the peri-tracheostomy defect; $(B)$ the second skin paddle was adapted to floor of the mouth 


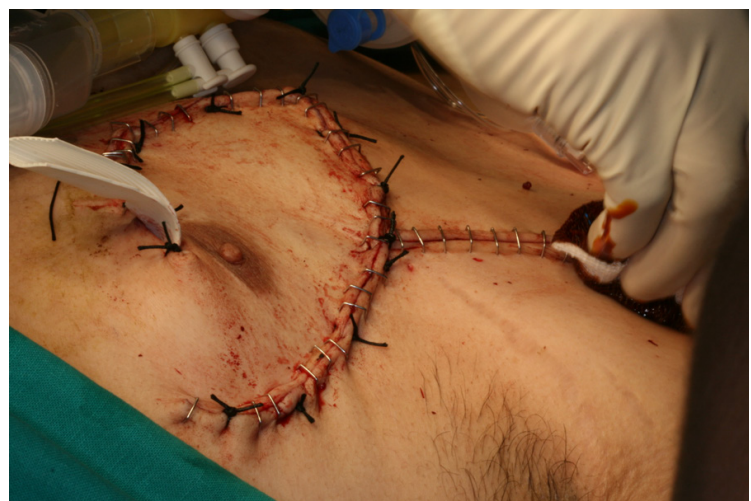

Figure 4: The donor site was closed primarily and remained intact throughout the post-operative period

in two layers (muscle-basal mandible and skin paddleoral mucosa) [Figure 3B]. The donor site was closed primarily and there were no dehiscence defects during the post-operative period [Figure 4]. Both skin islands remain viable to date [Figure 5].

\section{DISCUSSION}

Reconstruction of complex oral cavity defects following oral cancer surgery is a great challenge for the head and neck surgeon. The evolution of myocutaneous and free flaps has achieved good results in the reconstruction of large oncological defects. Currently, microvascular free flaps are considered to be the first option in the reconstruction of head and neck defects. However, in cases of free flap failure or when a free flap is simply not feasible, pedicled flaps provide a reliable alternative with predictable results. The bilobular or double-paddled PMMF simplifies the closure of large surgical defects of both the mucosa and skin which cannot be successfully closed in a primary approach. The closure of defects using a PMMF was first reported in 1979 by Ariyan. ${ }^{[4]}$ This author also described the division of the skin into two parts. Ord and Avery ${ }^{[5]}$ later suggested that placing the skin paddles side-by-side horizontally was less risky than placing them vertically one above the other. The two lobes of the pectoralis major myocutaneous flap evolved from a desire to simplify the closure of large surgical defects of both the mucosa and skin that could not be satisfactorily closed primarily. The mucosal and skin defects are closed by two skin paddles supported by a single muscular vascular pedicle.

In the current case, the double-paddled PMMF was used to reconstruct both intraoral and cervical defects. The distal paddle was adapted to the floor of the mouth and the proximal skin paddle was used to close the cervical skin and the peri-tracheostomy defect. The main advantages ${ }^{[6]}$ of the double-paddle PMMF include: (1) easy access within the same surgical field;
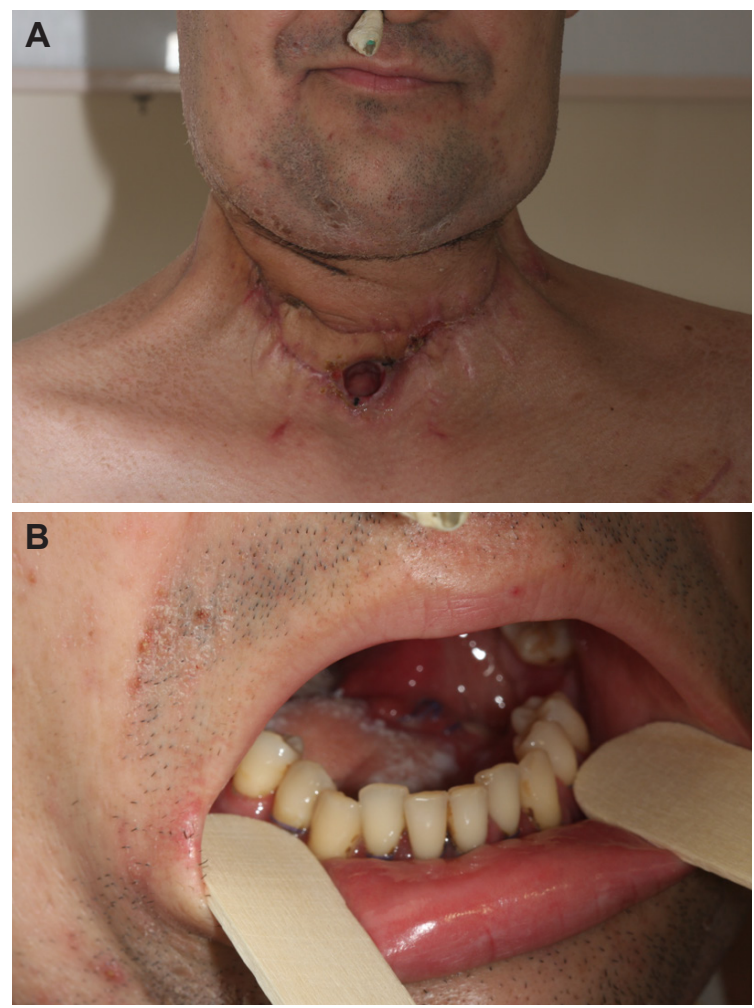

Figure 5: $(A$ and $B)$ Both skin islands remain viable to date

(2) shorter operating time; (3) elimination of the need for two separate flaps and a second surgical procedure; (4) technical simplicity with a short learning curve; (5) a reliable vascular framework; and (6) adequate muscle coverage of major cervical vessels, which provides greater protection during radiotherapy. Nonetheless, the success of this flap depends on the arch of rotation and anatomic limitations such as obesity, or the combination of a long neck with a short thorax.

In summary, the double-paddled PMMF can be successfully used for reconstruction of complex head and neck cancer defects following failure of microvascularized free flaps or when free flap harvest is not possible.

\section{Authors' contributions}

Manuscript preparation: M. Moreno-Sánchez, R. González-García

Manuscript's review: R. González-García, C. MorenoGarcía

Concept design: R. González-García

Literature review: M. Moreno-Sánchez

Financial support and sponsorship

None.

\section{Conflicts of interest}

There are no conflicts of interest. 
Patient consent

Written informed consent was obtained from the patient.

\section{Ethics approval}

According to the requirements of the affiliation, this article does not require case ethics approval.

\section{REFERENCES}

1. Towpik E, Meyza J. The "double faced" pectoralis major island flap. A valuable alternative in full-thickness cheek reconstruction. $J$ Craniomaxillofac Surg 1990;18:85-7.
2. Gadre KS, Gadre P, Sane VD, Halli R, Doshi P, Modi S. Pectoralis major myocutaneous flap-still a workhorse for maxillofacial reconstruction in developing countries. J Oral Maxillofac Surg 2013;71:2005.e1-10.

3. Teo KG, Rozen WM, Acosta R. The pectoralis major myocutaneous flap. J Reconstr Microsurg 2013;29:449-56.

4. Ariyan S. The pectoralis major myocutaneous flap. A versatile flap for reconstruction in the head and neck. Plast Reconstr Surg 1979;63:73-81.

5. Ord RA, Avery BS. Side-by-side double paddle pectoralis major flap for cheek defects. Br J Oral Maxillofac Surg 1989;27:177-85.

6. Bhola N, Jadhav A, Borle R, Khemka G, Kumar S, Shrivastava H. Is there still a role for bilobed/bipaddled pectoralis major myocutaneous flap for single-stage immediate reconstruction of post ablative oncologic full-thickness defects of the cheek? Oral Maxillofac Surg 2015;19:125-31 